\title{
Condução e danças de salão: Conducorporificação
}

\section{Leading and social dances: Embodied-conduction}

\author{
Rodolfo Marchetti Lorandi ${ }^{1}$ \\ Bianca Scliar Cabral ${ }^{2}$
}

Submetido em 9 de abril e aprovado em 14 de maio de 2019.

\begin{abstract}
Resumo: Este artigo busca, entre práticas, teorias e pesquisas artísticas e pedagógicas, especular sobre aspectos da condução nas danças de salão. Busca-se em conceitos no fazer, em experiências da Grão Companhia de dança, no diálogo com outros artistas e com a filosofia processual de Manning e Massumi discutir: o que é condução, onde nascem os movimentos em condução, o que são movimentos validados pela condução para, por fim, sugerir aspectos para uma pedagogia da condução nas danças sociais. Desse modo, através de conceitos como movimento-relação, corpo-mais-que-um, eventos em-formação, busca-se aqui demonstrar o complexo de relações que corporificam o movimento e que chamamos de conducorporificação.
\end{abstract}

Palavras-chave: Danças de salão. Condução.Teoria da Dança. Pesquisa-criação.

Abstract: This article seeks, among practices, theoretical, artistic and pedagogical research, to speculate on aspects of leading in social dances. It seeks to discuss, by raising concepts in the making, through the experiences of Grão Companhia de Dança and in the dialogue with other artists, with the process philosophy of Manning and Massumi: what is leading in dance, where do the movements in leading begin to emerge, which are movements validated by leading, finally, to suggest aspects for a pedagogy of the leading in the social dances. In this way, through concepts such as movement-relation, bodymore-than-one, events in-formation, we try to demonstrate here the complex of relations that embody the movement and that we call embodied conduction.

Keywords: Social dance. Leading in dance. Research-creation. Dance theory.

\section{Introdução}

‘Alguém filmou?', perguntava Lidiani Emmerich em ensaios da Grão Companhia de Dança, curiosamente, nos momentos que tornar-se-iam mais relevantes, onde ninguém havia de fato registrado os experimentos. Eram jogos de improviso com os quais a companhia movia-se entre consignas de relação, atenção, condução e dança de salão. Experiências que desdobravam em discussões infinitas, conceitos ou fissuras que se abriam em mais 
movimentos. Entre as proposições, experimentações e conversas, o vislumbre do caos, uma porção maior do que o próprio grupo e um recorte daquilo que se sentia e apontava para a certeza de que havia um excedente na experiência, um mais-que para além de qualquer ponto de vista passível de ser descrito, controlado ou mesmo "gravado".

Pedimos somente um pouco de ordem para nos proteger do caos. Nada é mais doloroso, mais angustiante do que um pensamento que escapa a si mesmo, ideias que fogem, que desaparecem apenas esboçadas, já corroídas pelo esquecimento ou precipitadas em outras, que também não dominamos. São variabilidades infinitas cuja desaparição e aparição coincidem. São velocidades infinitas, que se confundem com a imobilidade do nada incolor e silencioso que percorrem, sem natureza nem pensamento. É o instante que não sabemos se é longo demais ou curto demais para o tempo. Recebemos chicotadas que latem como artérias. Perdemos sem cessar nossas ideias. E por isso que queremos tanto agarrarmo-nos a opiniões prontas. Pedimos somente que nossas ideias se encadeiem segundo um mínimo de regras constantes, e a associação de ideias jamais teve outro sentido: fornecer-nos regras protetoras, semelhança, contiguidade, causalidade, que nos permitem colocar um pouco de ordem nas ideias, passar de uma a outra segundo uma ordem do espaço e do tempo, impedindo nossa "fantasia" (o delírio, a loucura) de percorrer o universo no instante [...] É tudo isso que pedimos para formar uma opinião, como uma espécie de "guarda-sol" que nos protege do caos. Nossas opiniões são feitas de tudo isso. Mas a arte, a ciência, a filosofia, exigem mais: traçam planos sobre o caos. (DELEUZE E GUATTARI 2010, p. 237)

E daqui continua-se. É importante considerar que nos movemos movidos juntas(os), na direção do caos que compõem esse texto e de onde emergem suas possibilidades de existir, rumo ao que é condução. O princípio da ideia de condução poderia indicar uma separação entre os corpos que dançam juntos, mas o que procuramos apontar ao longo deste texto é que isso não equivale à experiência de quem dança à dois.

No exercício de isolar este fator, encontramos um movimento de corpos que são, desde o começo, sempre mais-do-que-um ${ }^{4}$. Deste modo corporifica-se na forma 
da dança uma escrita aparentemente estável, composta do vocabulário de passos e acordos, mas que emerge de um plano virtual já em movimento, a partir do qual o fluxo se segue, imanentemente, criando novidades e possibilidades.

A condução não é um movimento com fim em si mesmo, nem início, ou em branco, mas a soma de fatores de fluxo (direção, intensidade, peso, ritmo, etc.), de interferências possíveis (existências, qualidades, tonalidades, meios, etc.) e de todas as suas possibilidades que já se conduzem em planos relacionais (pré-movimento e pré-linguagem). Se, como escreveram Deleuze e Guattari, uma tela em branco nunca é vazia, mas uma extensão do infinito potencial de possibilidades, do mesmo modo, o que chamamos de condução não se impõe em um instante vazio, onde o movimento cessou ou começou (2010). Ela não ocorre instaurando uma ação a partir do nada, mas atualiza potenciais, forças, tendências, existências, possibilidades e novidades.

Notamos que condução na dança de salão é frequentemente tratada como princípio de ordem, hierarquia, forma, o que desconsidera aqueles e aquelas que dançam e as especificidades do movimento partilhado por decisões de instante. Por isso, este artigo esclarece a necessidade de a entender a partir de um espectro mais amplo, expresso através de uma linguagem falha, que insistimos em utilizar para falar de tudo o que compõem a experiência dançada. Partimos de práticas, experiências no fazer, dos conceitos que emergem das relações de dentro dos acontecimentos, para falar que esta aproxima-se da noção proposta na filosofia de José Gil, de que "dançar é fluir na imanência"5, e que, portanto, elucida-se um "corpo virtual" e revela-se um movimento "infinito infinito", tal como descreveu Manning (2014).

A sugestão é que na delimitação deste fator podem ser revelados "eventos-emformação", Manning (2008), por exemplo, quando em um abraço com outro corpo o encontro nos leva para um quarto lugar, ou seja, não nos movemos apenas pelo resultado de forças físicas ou códigos das linguagens de dança. Quem conduz não é aquela ou aquele que arquiteta, quem segue não é aquele ou aquela que recebe. Há um lugar terceiro, onde a relação já se conduziu antes e dentro do abraço, na direção de uma quarta possibilidade, que é o movimento instaurado em direção do próximo passo ou de um novo lugar pelo espaço, e não da direção final de uma tomada de decisão 
anterior. Este quarto espaço só tomamos conhecimento ao chegar, é para lá que fomos impulsionados, entrelaçando-se no infinito-infinito do mover-se com o salão.

Quando dançamos, mesmo quando apoiados em um vocabulário tradicional de movimentos, é perceptível que um conjunto outro de movimentos para além dos conhecidos e tendências brotem o tempo todo, de algum lugar inexplicável que regras de conduta nos impedem de ver. Esse lugar é o plano virtual de infinito infinito. Aqui encontramos o que Massumi define como a "topologia da experiência", algo que não é localizável, mas instaurado através da cinética do instante (2016). Dançar no mundo é trazer para a relação o movimento do mundo. É realizar um passo ao lado sem nunca ter tido a necessidade de se ver dono desse passo, pois isso seria uma ilusão formal, muito menor do que a dança e seria desconsiderar questões importantes no movimento das relações.

Mesmo certos, ainda assim, de que era a única possibilidade de nos movermos juntos(as) naquele momento, quando o movimento acontece, quando realmente não há possibilidade de outra coisa acontecer, um sentimento nos enche de satisfação. Mas o que propomos é que não haveria outra possibilidade que não essa, posto que as ações corporificadas através das inclinações e ativações, que chamamos de condução, nos trouxeram dessa forma. Não fosse assim, tentaríamos na dança forçar para dentro da relação algo que não está presente naquela ocasião, trazendo para o fluxo do movimento uma 'vontade' ou intenção externa. Neste sentido, executar um desenho, uma forma prévia ao longo da intenção de fluxo à dois não é o que determina nem o que sugere condução, pelo contrário, está no núcleo dos desenhos que se formam. Em outras palavras sugere uma possibilidade de perceber, em um estado de atenção, que nos moveremos sempre a partir do entre, em complexas relações sentidas no fazer.

Antes de se efetuar passos finitos na dança, o que ocorrerá em estágios posteriores deste instante, ocorre uma corporificação de uma relação complexa, movendo-se, onde o movido é também movente. Sob esta perspectiva perguntamos o que é condução, onde nascem os movimentos em condução, o que são movimentos validados pela condução e o que sugere uma pedagogia da condução? 


\section{O que é condução?}

O relato da artista Amanda Bagss sobre linguagem é preciso para falar desse corpocondução-em-formação, onde seu instante emerge na fissura das linguagens de dança. Baggs, diagnosticada no espectro do autismo, descreve que percebe o mundo nas muitas possibilidades de ser, e aponta: "ironicamente, o jeito como me movo ao responder a tudo ao meu redor é descrito como estar em meu próprio mundo (...). Enquanto que se eu interagir com um conjunto muito mais limitado de respostas e só reagir a uma parte muito mais limitada do meu entorno, as pessoas afirmam que estou abrindo uma verdadeira interação com o mundo" (BAGSS, 2007, apud MANNING, 2008, p. 2, tradução nossa)7.

Manning reforça que, para Baggs, a comunicação através da linguagem permanece inadequada às experiências singulares de sensação que o mundo exprime, onde aquilo que seria articulável na forma não alcança completamente a complexidade da experiência (2008, p. 2). A analogia com nossos apontamentos aqui, destaca as implicações cruciais para os estudos da dança ao considerar que movimentos nascem em estágios posteriores aos eventos, formalizados nos elementos concretos que conhecemos como passos, poses, posturas, figuras, formas e que são uma abstração do mais-que em jogo em cada uma dessas atualizações. Uma política da condução destaca as relações verdadeiras de interação para além das limitações baseadas nas linguagens que definem modos individuais de interagir. O movimento das relações parte de como estes corpos são compostos a partir do plano virtual, dos resíduos que poderão ser corporificados na intensificação do entre-com. Este seria o plano de criatividade de onde surgem os seus primeiros estágios, uma força ainda disforme, modulada pelo evento e que nomeamos de conducorporificação.

Nos toca a afirmação que tensiona os limites entre sentidos e indicativos narrados da experiência: "Há algo sobre a experiência de Baggs que nunca saberemos, porque saber é sentir. (...) O que Amanda Baggs faz é começar a nos ensinar a articular o pensamento do sentir". (MANNING 2008, p. 2). Há algo em condução que pode ser sentido, que fala dos(as) outros(as) e que não saberemos. Manning descreve que "A comunicação através da linguagem sempre será curta. Ainda assim a linguagem é capaz de transmitir uma certa complexidade dos conceitos em jogo, conectando os mundos de tal forma que o diálogo entre os mundos-em-formação pode ser iniciado" (MANNING 2008, p. 2). Na sua 
complexidade, condução não indica um ponto final, tampouco inicial, para o movimento à dois. Nos limites da linguagem em que toma forma, não está em jogo apenas uma direção, ou direcionalidade, mas o destaque de um espaço para aqueles(as) que dançam aterrissarem juntos(as) em uma nova suspensão, originando incessantes novas formas por vir.

Este espaço de in-formação pode ser descrito como o ambiente em movimento, em "uma multidimensional multiplicação de eventos-em-formação" (MANNING 2008, p. 1) que, como plano potencial, já contém formas e movimentos. Na suspensão da condução os sentidos podem ser processados na complexidade ambiente. Sim, é claro que estamos empenhados em responder, ao dançar, aos aspectos curtos da linguagem (direção, velocidade, peso, forma, tempo, ritmo), mas é necessário que se perceba tantos os vetores de forças suspensas na relação, como vetores virtuais de potencialidade e tudo aquilo que já se efetuou no movendo-se entre-com.

A suspensão provocada pela condução é um entrelaçamento entre "o que é absolutamente aquilo o que se tornou ou está se tornando (uma ocasião actual) e o que está no campo do potencial e pode se expressar" (WHITEHEAD 1978, apud MANNING, 2014), em outras palavras, tendemos a notar os efeitos destas forças na experiência, tensionados no campo virtual da pré-linguagem e do pré-movimento. Por fim, podemos afirmar: não é linguagem, não é composta por direcionalidade, não se limita aos movimentos a que contribui para surgir. É, de fato, o movimento movido e movente a partir de eventos-em-formação que emergem da experiência pelas fissuras das linguagens das danças, danças de salão - é conducorporificação.

\section{Onde nascem movimentos em condução?}

Era um baile, por volta de 2012, uma dança pelo salão com a bailarina Sheila Ludwig $^{8}$ e que foi fundamental para nossos argumentos aqui apresentados. Uma dança, qualquer que seja, vista como acontecimento, é capaz de questionar a ideia de um sujeito desta dança. Tanto nessa ocasião, como em outras danças, percebe-se que o que se sente, ao longo de como se desloca pelo salão, muda de forma inúmeras vezes e para além do que podemos notar. Há poucos anos, e ao longo da história da dança de salão, era muito mais comum uma falsa direcionalidade da condução, como no princípio 
(crença) repetido de que 'homens conduzem, mulheres respondem', por exemplo, ou um ensino que se apresentava como se fosse uma questão de técnica a ser executada por um corpo pronto para se relacionar e sugerisse uma preparação formal (treinamentos e linguagens formais).

Mas a dança, a qual nos reportamos, indicou um problema, pois nos pressupôs que ninguém conduziu aquilo que de fato tomou forma. Mas se ninguém conduziu naquela dança de passos de Samba de Gafieira, então como foi partilhado o movimento? Seria o salão, ou os espaços vazios ou preenchidos por outros corpos em fluxo? As formas do corpo se alterando? As projeções de corpos que se atualizavam ou não? Um braço de Sheila que parecia ir além? A projeção de uma perna que nem saiu do lugar? Um vetor de força pela coluna? Um arco de abraço que ia para além dos que os braços alcançavam? Questões sociais, de gênero ou fissuras nessas relações mudando suas formas de dentro? Seria o desejo corporificado de deslocar pelo salão com roupas esvoaçadas? Seriam os movimentos que uma calça volumosa sugeria? O desequilíbrio que o salto provocava antes do corpo se inclinar por ali?

Cada um destes elementos para além e aquém compõe indícios dos virtuais e actuais que impulsionam a forma, que são potenciais relacionais e que, em eventos-emformação, nos corporificam já em movimento, o infinito infinito de tudo aquilo que dança entre nós e nos move em uma ocasião actual. Seria um equívoco indicar apenas que Ludwig conduzia a ser conduzida, pois a análise que indicamos aqui é que condução não tem de fato uma direção, não é o que toma forma, e suas fissuras já estão presentes em qualquer linguagem de dança de salão, onde irão sempre ocasionar relações outras para além do que sujeitos insistem em discursar.

Gil (2001) descreve que Steve Paxton, um nome importante na emersão do contato improvisação como dança de parceria, dizia haver um momento de suspensão na relação e uma suposição de induções mútuas entre as duas ou os dois dançantes. Ali, em 1970', por não haver uma sustentação de forma prevista, já podiam ser tocados os parâmetros que discutimos aqui no cosmos da condução. A ida em direção ao passo, mantém as suas aberturas dentro deste fluxo. David Lapoujade em seu livro, As Existências Mínimas, destaca que "no cosmos das coisas, há aberturas, inúmeras aberturas desenhadas pelos 
virtuais" (2017, p. 44). Na dança de salão, os vocabulários partilhados guardam ainda estas fissuras, articuladas através da variação de intensidades que emergem, travessias e enunciações do movimento movido.

Movimento do corpo, do pensamento, da percepção, entre planos virtuais e actuais, revelam tendências. Entre cada passo, forma movida, permanecem vetores potenciais que precedem as actualizações e que sugerem um plano virtual como criatividade. Não há uma criatividade fora do que já está inscrito, não há um sujeito da criatividade, mas um potencial de novidades a partir da decisão compartilhada, que leva às variabilidades de formas da dança por vir. Esta criatividade percebida, sugere Manning (2014) chama nossa atenção, incita a um direcionamento na improvisação movida. A condução, em sua melhor expressão, cria um complexo potencial, e só pode operar as alterações sugeridas a partir de modos de atenção à relação e à sua sensação de emergência. Lapoujade escreve que “percepção é participação. Um fenômeno surge, surpreende por sua beleza, e lá estamos nós presos no interior de uma espécie de monumento perceptível do qual exploramos a composição momentânea" (2017, p .47).

Nessa participação do acontecimento é que sentimos o mundo em condução e que não se estabelece a partir de uma diretividade de códigos, a serem respondidos ou, pior, obedecidos, mas sim a partir de um jogo intercambiável de sensações. Deleuze e Guattari (2010, p. 250), descrevem que "a sensação é contemplação pura, pois é pela contemplação que se contrai, contemplando-se a si mesma à medida que se contempla os elementos de que se procede. Contemplar é criar, mistério da contemplação passiva, sensação". Eles completam: "A sensação preenche o plano de composição, e preenche a si mesma preenchendo-se com aquilo que ela contempla" (DELEUZE E GUATTARI 2010, p. 250).

A noção de uma contemplação ativa é fundamental para a compreensão proposta aqui, pois não se trata de um "entendimento" de uma informação qualificada, mas de uma contemplação à dois-mais-que-um, que move a intensidade das decisões sobre um futuro movimento, posterior àquele porvir. Assim só é possível estar nessa complexa relação, se as fissuras forem sintonizadas em modos de atenção de ambos e em acordo com o meio. Note que quando não há esta operação, a gestão do movimento já foi decidida previamente 
por aquele ou aquela que supostamente seria condutor(a) ou conduzido(a), uma mentira, crença, e que delimitaria o reconhecimento de informações a serem indicadas por códigos formais "adquiridos". A atenção ao potencial criativo do meio, à linguagem fissurada para com os acontecimentos e instantes permitem que uma verdadeira ecologia ${ }^{9}$ do salão de dança aconteça e é deste complexo que emergem os corpos que, de fato, dançam juntos.

As proposições dadas em movimento fazem um "movimento de dobra" como descreve Massumi (2016), uma deformação contínua, ação sobre ação. O mover-movido toca o potencial criativo para emergir de volta em mais movimento, ao extrair de lá um impulso que irá arremessar os corpos para direções outras, explica o filósofo em sua análise (2016). Massumi, ao descrever como as alterações de movimentos predispostos ocorrem na experiência, ressalta a sutileza destas alterações como uma intenção, uma tonalidade que indica e que pode produzir um corte "na intensidade vibratória do corpo virtual, arremessando um estilhaço de experiência, que passa depois a destacar-se do segundo plano integral da variabilidade de experiência do qual veio" (MASSUMI 2016, p. 17).

Estas intensidades é que compõe ou indicam condução. Se analisarmos um instante qualquer do movimento, iremos notar que se desfaz, de fato, sua origem e sua direcionalidade e, portanto, a não ser que estivéssemos analisando uma dança "truncada", como se dois bailarinos mostrassem suas vontades discursivas de passos, na verdade percebemos um contínuo onde os indicadores são inseparáveis do fluxo seguinte, dobram-se em deformação contínua com os outros corpos do salão, com a música, com o ambiente, etc.

Citamos aqui, complementarmente, uma performance realizada em 2014, da Cia Grão, onde eram utilizadas vendas ao longo de um experimento performático. Todo o grupo se propôs a dançar os encontros que emergissem a partir da restrição à visão. Mesmo com a restrição, percebeu-se que os códigos de dança de salão se mantinham, porém sem determinismos, sem hierarquias ou formalidades. Sem a visão, pouco se controlou de direções, com quem ou com quantos se dançaria, os movimentos eram verdadeiros estilhaços de co-composição. A sensação é que o grupo não escolheu quais estratégias utilizar, nem se era vertical, horizontal ou por cima de alguém ou alguma coisa. Foi este, talvez, um momento importante para o grupo perceber o infinito de variáveis que um 
evento corporifica nas escolhas que vemos nas formas da dança a partir de uma conduçãoem-formação.

Esses planos não referenciam um sentido espacial, são um "campo de emergência da experiência: sua gênese, seu intervalo imperceptível de formação", relata Massumi (2016, p. 17). Distintos de um projeto coreográfico, compõe um acontecimento, um evento-em-formação, que não dá ao corpo coordenadas, mas emergem a percepção de um movimento sempre em relações outras, que implicam em uma topologia ${ }^{10}$ do moverse entre-com.

\section{O que são movimentos validados pela condução?}

Movimentos são compostos de sensação que se co-criam com as linguagens e carregam suas fissuras, recheadas de virtualidades de onde emerge a condução validada por um estado de atenção. São um conjunto complexo de tendências, acordos, linguagens, planos virtuais e reais, que se conservam em si, mas não se limitam a si nem a quem está presente. Estes movimentos-compostos revelam o plano do qual emergem e se mantém abertos ao mundo.

Para falar dos passos, movimentos comuns nestas danças, é preciso falar de quando estas danças não são em pares ou são quaisquer pares ou trios (sem definição de gênero, por exemplo), como em duas mães e sua filha em sua formatura, ou dois pais e seu filho em uma Valsa de 15 anos. Como em um grupo, em uma dança de salão de roda no espetáculo Moebius (Grão Companhia de dança, 2014), ou em duas cadeirantes ${ }^{10} \mathrm{em}$ uma performance de Zouk no Rio de Janeiro.

A dança de salão dos 'trios', como se discute na Grão, não é tratada como um educativo, pois não parte de um princípio de ensino fragmentado entre sujeito e eventodança - é tratada como dança de salão sempre, em todas as suas variabilidades. E é nos trios, ou grupos, como práticas comuns às danças sociais e que não se limitam a dois, que a Cia Grão começou a notar condução para algo além de um binômio de obediência. Em resumo, nos 'trios', três pessoas estão em relação, em fluxo e no fluxo do trio e dos eventos que surgem, alternando modos e estratégias propostas e emergentes. As consignas ou estratégias são infinitas. E algo chama a atenção, quanto mais complexa a relação com 
o mundo, maior a atenção aos eventos e mais validamos os(as) outros(as) e as relações, validamos uma tecnicidade para além de nós.

A dança de salão social usualmente acostumou-se a se estruturar a partir de preceitos técnicos, vocabulários adquiridos e tensionados em modos de fazer específicos. Entretanto, a perspectiva que se defende aqui, demanda que consideremos a ideia de tecnicidade, através da qual se nota, ao longo da última década, que pouco importam os passos realizados quando a relação é o fim. É o que acontece quando não se prioriza a técnica e quando não se definem papéis e formas a serem executadas.

Tecnicidade sugere um "movimento sempre ativo além da estabilidade de sua iteração passageira". Há algo além da forma que é uma força e essa força "de movimentomovente tem uma qualidade inefável, uma qualidade - uma tonalidade afetiva em movimento - que toca o limite do movimento como força de forma, mudando a dança para um lugar da invenção momentâneo. Não é o sujeito inventando, mas o movimento inventando", escreve Manning (2014).

Quando a dança à dois notou suas existências e passou a ser experimentada entre duas pessoas ou uma, ou três, grupos, sociedade, ambiente, relação sempre mais-que-um, ecologias, necessidades de controle se dissolveram pela satisfação outra em validar o potencial relacional. A satisfação no potencial do movimento na incipiência de seu devir relacional, na tecnicidade.

Em 2017, durante a performance 'Segunda Pele' (Coletivo Lugar Comum PE), a artista $\mathrm{M}^{\mathrm{a}}$. Clara Camarotti tira toda a roupa enquanto relata cortes que o médico fez para tirar aquilo que ela (e sociedade) viam como excesso de peso. Enquanto despia-se das roupas e lembranças, nos conduzia para além das porções de peles e cicatrizes, nos impulsionava ao mundo e à sociedade que já estavam ali antes mesmo de ela se despir. Ela diz: 'não foram os cortes dos médicos os primeiros que eu recebi. Os primeiros cortes foram os cortes dos olhares'. Ela falava de nós, e falava dos cortes da percepção ao entrar, falava dos limites da percepção e de como a avaliamos como mulher. Os cortes da dança de salão agem de forma similar, ensinam por formas e educativos, não edificam corpos engajados no mundo, falam mais de si do que daquelas pessoas no momento em que dançam. Camarotti ensinava condução de dentro, e era preciso se despir de si para dançar com ela e com Baggs na experiência ${ }^{12}$. 
Movimentos de dança de salão que nascem para fora da relação são como cortes do olhar, são tentativas de inserir no acontecimento aquilo que não é seu potencial. Em outro exemplo, uma aula ${ }^{13} \mathrm{em} 2018$, em uma conversa ao fim, após os trios, uma aluna comentou: 'foi interessante como a minha colega não sentiu minha indicação, estava se movendo sozinha, sem a minha condução'. Amanda Bagss e Maria Clara Camarotti falam sobre o sentir, e o engajar, que a aluna ainda estava entendendo, que sentir era se despir de si para entrar em relação pela atenção e não pela forma. A outra aluna, que ela acusava de não sentir, tinha uma limitação que não permitia o corpo dela seguir na direção que arquitetou de fora, direção para além do evento, mas afinal será que a limitação não poderia ser na dificuldade da 'condutora' em ceder à vontade daquilo tudo que já se movia?

Passos são a conducorporificação da dança da condução na relação. Movimentos corporificados em rede com o ambiente emergente. Ao dançar, criamos blocos de sensações, que vão se tornar catalisadores de novos eventos para além da presença daqueles que participaram dos eventos anteriores. Maria Claudia Reginato, também bailarina da Grão, escreve que 'o respeito ao corpo-movimento e a relação em cada apresentação, com seus colegas, sem expectativas, faz cada vez ser única' e define assim um corpodança. Ela se refere à performance-diálogo Karma ${ }^{14}$ (2016), que acompanha a oficina citada anteriormente, mas também aos trabalhos com a Cia Grão.

\section{O que sugere uma pedagogia da condução?}

Co-compor e ensinar danças de salão é olhar para os movimentos dessas linguagens pela perspectiva da experiência, edificando blocos para além dos aspectos curtos de seus códigos, buscando uma atenção de dentro ao que se compõe, na incipiência dos eventosem-formação. Frequentemente, se percebe a condução sendo reduzida à um status de códigos, nos determinismos e engendramentos de gêneros-conduta, artístico-sociais, político-filosóficos daqueles que dançam, ou pior, ditando como o deveriam.

O que propomos é que sua pedagogia trate de compor em si e desvie da exclusão das sutilezas que dançam a experiência de mundo. As danças de salão falham, ainda que por um breve instante dançado, usualmente quando se abstrai a complexidade dessa 
ecologia de práticas e que sugere uma atenção aos eventos, uma tecnicidade peculiar ao encontro, particular àquela única dança dançada por um instante. É necessário, sob esta ideia, o ensino de dentro da condução e uma política da condução, e não um fim em formas isoladas, as "figuras", nem em papéis, muito menos em movimentos finitos com fim em si ou sua execução como forma pré-estabelecida.

Aproximamo-nos neste sentido das implicações em assumir na dança de salão o espectro de uma pedagogia radical ${ }^{15}$, como proposição que edifica experiências no mundo, (Scliar, 2016). Entende-se por pedagogias radicais a partilha de blocos de sensações instáveis em suas formas pois permitem variáveis em suas singularidades. A proposição, no campo do ensino do movimento destaca que "o cuidado com as condições permissivas constitui um dos motes para as pedagogias radicais. São elas que viabilizam o mergulho-potencial no processo de estudo" (SCLIAR 2016, p. 16). Neste sentido nossa preocupação é em restaurar as vertentes para um ensino da condução que não sejam lineares, deterministas e estabilizadas a partir de formas, o que, de fato, enclausura o aspecto mais precioso da relacionalidade na dança de salão.

Sob esta perspectiva relatamos uma aula, do projeto 'aulas entrecruzadas' ${ }^{16}$, onde era ensinada uma sequência de movimentos no gênero Forró. Já no primeiro momento, cada dupla da sala fez ajustes singulares dentro da sua relação, a partir dos eventos em seu entorno, que abriu potencial para outros movimentos, criando caminhos para além do que foi tendenciado, ou planejado, como aula. De fato, tudo indica que isso sempre acontece, porém dessa vez não o fora abstraído do momento, esta questão, como é de costume nas danças a dois, pelo contrário, tornou-se o foco agrupar aqueles ajustes e ir para onde aqueles corpos já estavam indo, permitindo que as novidades, e existências que surgiram, se mantivessem na pesquisa tanto quanto estas aberturas dos movimentos por vir.

Podemos perceber nos passos de dança um "equilíbrio precário" de forças atuando, um equilíbrio de palavras, posições, ritmos, pausas, espaços, conceitos, formas nada estáveis se compondo o tempo todo, e compondo significados. Movimentos compostos por variação do infinito virtual, "por um infinito número de micromovimentos, movimentos tão minúsculos que são quase imperceptíveis, mas também de movimentos virtuais - intervalos, intensidades, forças”, escreve Manning (2014). O tomar-forma 
daquilo que dança, não reside num sujeito humano, mas em uma complexa relação de mundo, é um tomar forma nas ecologias da vida-vivida ${ }^{17}$ como em Manning (2014). Aquilo que toma forma, passos, gêneros, movimentos e condução, se corporifica nesse caos e assume modos de co-implicação a cada variação e instante. Sua pedagogia, sugerimos, implica em trabalhar diretamente a partir deste tomar forma, in-formação, implica uma política da condução-em-formação.

Danças não perdem sua identidade no devir que as compõem, pelo contrário, atualizam suas existências e variabilidades. Rompem fronteiras formais e estéticas todo o tempo, desde sempre, para qualquer desses universos, bem como entre artes e as suas pedagogias e em cada disciplina (ou tomar forma), está sempre em relação com seu entorno, suas variáveis, as não disciplinas, o infinito-infinito do que impulsiona seu próprio movimento.

\section{Considerações finais}

Estamos dançando, fazendo filosofia com dança, ciência com dança, arte com dança, construindo um conhecimento singular que fala e pergunta sobre o que é condução a partir do mundo vivo, de eventos-em-formação como sujeitos da experiência, a partir de uma ecologia de práticas vivas de danças de salão que reconheçam o potencial relacional.

Generalizamos aqui o que são as Danças de salão na direção que vai além do que discursos de poder tentam engendrar posto que essas danças são danças-mais-doque-uma, que Conducorporificam corpos-mais-do-que-um. Forró, tango, zouk, samba, livre, etc., e seus infinitos universos em comunicação incluem as diversas práticas sociais, artísticas, clássicas, modernas, populares, contemporâneas e todas as suas misturas. Por nos atentarmos à análise e especulação sobre o infinito instante da condução, consideramos ser indistintas as diferenças de cada um dos gêneros em jogo.

Ao fim, não há um método para ensinar que seria mais eficiente, podemos concluir. Condução é aquilo que nunca poderá ser filmado, pois já passou e não tomou forma, é o caos do qual não precisamos nos proteger, pois dele se extraem todas as existências de um bailado. É algo que não tem direção, não se encontra na ordem do tempo. É um dado qualitativo de movimento, movido movente que atualiza forças, tendências, 
planos, potenciais e relações. É um evento-em-formação que corporifica, é um processo de conducorporificação a partir da vida-vivida, intensificada em cada volta no salão. Entra em ação como plano relacional pelas fissuras da linguagem, cria comunidades, nos aproxima do que é a experiência de mundo a partir da dança partilhada, potencializando a criação do mundo para além de uma relação de causa e efeito direta. A condução se dá naquele momento de suspensão do tempo, onde o devir do mundo é sentido em seu processo contínuo de criação, onde co-cria-se o movimento independente da forma, sugerindo atenção, movimento da percepção e participação.

\section{Referências}

DELEUZE, G. e GUATTARI, F. O que é a filosofia? Tradução de Bento Prado Jr. e Alberto Alonso Muñoz. São Paulo: Editora 34, 2010.

DELEUZE, Gilles. A imanência: uma vida. Revista educação e realidade. v. 27, n. 2, 2002. Disponível em: <https://seer.ufrgs.br/educacaoerealidade/article/view/31079> Acesso em 20 Abr 2019.

GIL, J. Movimento total: o corpo e a dança. Tradução de Miguel Serras Pereira. Lisboa: Relógio D’Água Editores, 2001.

LAPOUJADE, D. As existências mínimas. Tradução de Hortencia Santos Lencastre. São Paulo: Editora N-1 edições, 2017.

THAIN, Alanna. Affective Commotion Minding the Gaps in Research-creation In Inflexions - a journal for research creation. n 1. p. 1 - 24, may. 2008. Disponível em <http:// inflexions.org/issues.html\#i1> Acesso em 25 mar 2019.

MANNING, E. Percorrendo o mundo. Tradução de Bianca Scliar Cabral (no prelo). Original em Body \& Society. v. 20, n 1, p. 162 - 188, set. 2014. Acesso em: < https://journals. sagepub.com/doi/abs/10.1177/1357034X14546357?journalCode=boda $>$ Acesso em: 25 mar. 2019.

MANNING, E. The minor gesture. Durhan: Duke University Press. 2016.

MASSUMI, Brian. A arte do corpo relacional: do espelho-tátil ao corpo virtual. Tradução de André Fogliano. Revista Galaxia.n 31, jan./abr. São Paulo, Online. n. 31, 05 - 21, abr. 2016. Disponível em: $<$ http://www.scielo.br/scielo.php?script=sci_arttext\&pid=S198225532016000100005\&lng=pt\&tlng=pt $>$ Acesso em: 25 mar. 2019.

SCLIAR, Bianca C. Anotações sobre Pedagogias Radicais. Revista Nupeart. v. 16, p. 10 - 21, 2016. Disponível em: < http://www.revistas.udesc.br/index.php/nupeart/article/ view/10502> Acesso em: 25 mar. 2019.

WHITEHEAD, A. N. Processo e realidade: ensaio de cosmologia. Tradução de Maria Teresa Teixeira. Lisboa: Centro de filosofia de Lisboa, 2010. 


\section{Notas}

${ }^{1}$ Mestrando do programa de Pós-Graduação em Teatro da Universidade do Estado de Santa Catarina, Florianópolis, Brasil. rodolfolorandi@hotmail.com. A partir de sua pesquisa sobre condução e danças de salão, instaurou a problemática a respeito dos elementos da condução, bem como a estruturação da argumentação necessária para designar a argumentação sobre o 'dançar junto'.

2 Docente do programa de Pós-Graduação em Teatro da Universidade do Estado de Santa Catarina, Florianópolis, Brasil. Revisora das fundamentações teóricas e propositora dos conceitos relacionados à filosofia processual no contexto da pesquisa-criação. Orienta a pesquisa de mestrado que deu origem à formulação apresentada neste texto.

${ }^{3}$ Grão Cia de Dança (desde 2012) integrada por Rodolfo Marchetti Lorandi, Gabriel Ferreira, Lidiani Emmerich, Luiz Gabriel Catoira, Maria Claudia Reginato, estuda danças de salão e seus diálogos com artes, complexidade, condução e o movimento das relações. As suas principais obras são: o espetáculo 'Moebius' (2014), performances em redes, confluências (desde 2016) e o projeto correspondências (desde 2018). Moebius é um espetáculo que tem como premissa uma dança de 'escolhas e percursos' e foi inspirado no trabalho de Maurits Cornelis Escher e eu sua representação dos caminhos e mundos impossíveis.

${ }^{4} \mathrm{O}$ conceito de um corpo mais-do-que-um é proposto por Erin Manning em sua teoria filosófica que sugere que um corpo nunca preexiste seus movimentos e nunca se limita a tudo que o compõe. Um corpo é sempre in-formado pelo evento que o cria e excede a si mesmo, nunca é antes do que se move e é no movimento que se corporifica. Excede a noção de sujeito e subjetividade, elabora Manning (2014), "nunca é menos do que o mundo que o co-compõe [...] ele sempre excede a soma de suas partes. Um corpo é sempre infinitamente mais que um". A autora conceitua como corpo-mais-que-um ("more-than-one").

5 Imanência é o plano do "corpo total" de Gil (2001), é o plano de onde surge cada "uma vida' que importa, seja qual for, em Deleuze (2002). É o plano de onde também emergem os virtuais, em David Lapoujade (2017, p. 37), que traz, segundo Étienne Souriau, o universo dos virtuais, onde "uma quantidade de esboços ou de começos, de indicações desenham, em torno de uma realidade ínfima e cambiante, todo um movimento caleidoscópico de seres ou de monumentalidades que nunca existirão". "Com os virtuais, toda realidade se torna inacabada. isso não vale apenas para o arco quebrado de uma ponte ou um esboço, mas para qualquer realidade, até mesmo a mais acabada, a mais concluída. O grande fato, diz Souriau, é incompletude existencial de todas as coisas. Nada nos é dado de outra maneira, nem nós mesmos, a não ser em uma espécie de meia luz, em uma penumbra onde se esboça algo inacabado, onde nada tem plenitude de presença, nem evidente patuidade, nem total realização, nem existência plena".

${ }^{6}$ Para Manning (2014), o infinito infinito é um plano virtual de potencialidade que não começa nem termina em seus movimentos, que não pressupõem algo ao fim ou anterior a um infinito e que não se limita aos movimentos finitos. É a ideia de um campo virtual como as possibilidades de as coisas, e os movimentos, existirem, e de onde se atualizam já em movimento. É quando dançamos e não temos a noção de um começo, nem um fim, nem de um sujeito das ações, completamente tendenciados por forças e possibilidades virtuais em movimentos contínuos.

7 O vídeo e a fala de Amanda Bagss pode ser visto em https://www.youtube.com/ watch? $=$ JnylM1hI2jc\&t=1s.

8 Sheila Ludwig é bailarina, artista que trabalha e reside em Florianópolis, SC. Sua presença naquelas danças, ou neste texto, modifica o que é dança e condução todo o tempo, assim como cada singular existência real ou virtual, evento, ocasião. Entender que, mesmo sendo uma bailarina que um olhar desavisado poderia rotular como tradicional, ela participa deste evento composto por inúmeras outras existências, um evento-emformação, que como tal rompe com qualquer noção dual e direcional sobre o que é e onde começa a condução. ${ }^{9}$ Manning (2016) pergunta o que mais a vida poderia ser, valoriza em seus conceitos uma complexidade que coloca o evento como importância maior. Ela explica que se refere a ecologia das práticas no sentido de um ambiente vivo, que se mantém na diferença, na não necessidade de um agente humano, onde a experiência está no tempo de vida, não na vida humana, mas sim mais que humana, a vida nos interstícios da experiência. Uma ecologia das práticas de condução perguntaria como em Manning (2014), "onde estou eu - no meio de uma ecologia de relações, dançando a dança que me dança".

10 Topologia no sentido de convergência, conexidade e continuidade. um espaço topológico que não pode ser representado como a união de dois ou mais conjuntos abertos disjuntos e não-vazios (Fonte: Wikipédia 2019).

${ }^{11}$ Como, por exemplo, no projeto 'Carioca sobre rodas' que acontece no Rio de Janeiro desde 2012

(Disponível em http://www.escolacarioca.com.br/site/carioca-sobre-rodas.html). 
12 "No contexto do ensino das artes a partir da perspectiva da performance, ao considerarmos as ideias de um empirismo radical é necessário não mais obedecer a manutenção de uma separação entre aquilo que é da ordem do treinamento do corpo e o que compõe a compreensão situada do lugar. Esta separação entre situação e processos contidos na experiência do corpo hierarquiza o ambiente externo (sócio-geográfico), que passa a ser um aspecto secundário no ensino de processos criativos do corpo [...] Sob a perspectiva da pedagogia radical, entretanto, há uma justaposição entre corpo e lugar e a pedagogia do movimento é determinada a partir de procedimentos que abraçam a problemática da presença do corpo simultaneamente com a articulação daquilo o que constitui o espaço. O corpo não deve ser aquietado para aprender, nem tão pouco a arte deve restringir-se a simbolizar, narrar algo a ser compreendido na estaticidade da experiência" (SCLIAR 2016, p. $14-15)$.

${ }^{13}$ A oficina 'ao começar em mim, começa em você, é sobre mim e sobre você', acontece desde 2016 e circula o Brasil desde então. É um projeto composto por Maria Claudia Reginato, Rodolfo Marchetti Lorandi e Dayane Ros. Em 2018, foi recebida pela Faculdade Regional de Blumenau. A primeira parte, em trios (A, B e C), as pessoas contam uma experiência de vida entre A e B, B e C e C e A. Após alguns minutos contando-a, a (o) colega conta de volta a 'mesma' história. A terceira pessoa observa. Troca-se as posições (A, B e C). Após essa troca falada, em trios, A e B manipulam o corpo de C, tentando encontrar os movimentos que o corpo de $\mathrm{C}$ já faz (ajustes, potenciais, inclinações). $\mathrm{C}$ vai aos poucos fazendo mais escolhas enquanto percebe as interferências e aumentam as manobras. A, B e C vão alternando os lugares de 'meio'. Na terceira parte, entram as experiências verbais da parte um, e os trios se conduzem dentro desse jogo complexo entre atenção, disponibilidade, fala, etc. Rapidamente, em todas as etapas, brotam eventos outros e ao fim se conversa sobre condução como evento - conducorporificação.

${ }^{14}$ Karma é uma 'performance-diálogo' (2016), dançada por Ma . Claudia e Rodolfo Marchetti Lorandi, que busca nos eventos um complexo de atenção movente que, 'como bolhas atemporais, guiam em cena' (Ver: https://goo.gl/ucSBos).

${ }_{15}$ Pedagogia radical, "mais que uma tendência pedagógica, sublinha processos de criação e educação estética, originária no fazer", relata Scliar (2016, p. 11). De acordo com Scliar, o termo relaciona dois eixos, um é o "possível diálogo e reformulação de condutas do pensamento social" e outra é o "amparo dos procedimentos de ensino e estudo na ideia de improvisação e de intuição" (SCLIAR 2016, p. 11).

${ }^{16}$ Aulas entrecruzadas é uma provocação, proposta por Rodolfo Marchetti Lorandi, que, como aula, acontece no Simpozio Cultural Campeche, em Florianópolis SC, desde 2018 e que têm origem em processos de aula da Grão Cia de Dança desde 2014. O projeto também faz parte da pesquisa/dissertação que dá origem a este artigo. Neste projeto, turmas de níveis diferentes se cruzam em seus horários, rompem as fronteiras e relações formais com os gêneros, gêneros de dança, tempo/duração da aula, códigos e onde observam juntos e juntas tudo que compõe aquela aula de forró, ou seja, fissuras que levam a discutir condução, gênero, sociedade, tomar um chá e falar da vida ou dançar muito forró e samba todos com todos, todas com todas, em pares, grupos, trios, etc.

${ }_{17}$ Movimento total é o campo do movimento em movimento, a força virtual do movimento enquanto percorre e se insinua em todos os deslocamentos reais, em todos os modos de tomar-forma e nas ecologias da vidavivida. Ver Manning (2014). 